\title{
Recent developments towards disposable screen-printed biosensors incorporating a carbon ink modified with the redox mediator, Meldola's Blue
}

\author{
R. Wedge ${ }^{1}$, R.M. Pemberton ${ }^{1}$, J.P. Hart ${ }^{1}$ and R. Luxton ${ }^{1}$ \\ ${ }^{1}$ Faculty of Applied Sciences, University of the West of England, Coldharbour Lane, Bristol. BS16 1QY, UK
}

\begin{abstract}
Screen-printed carbon electrodes (SPCEs) can be mass-produced at low cost and are readily adaptable as base transducers for incorporation into disposable biosensors. As biological recognition elements, the NAD+-dependent dehydrogenase enzymes have wide ranging application for the determination of many analytes in biological samples. In order to achieve the desired selectivity, it has proved necessary to reduce the overpotential required to electrochemically regenerate the cofactor, $\mathrm{NAD}^{+}$, by incorporating redox mediators into the carbon ink prior to screenprinting. One such electrocatalyst, Meldola's Blue (MB), has been used successfully and has been combined with dehydrogenase enzymes for the determination of some important biological analytes, including lactate, alcohol and ammonia. These examples from our laboratory using MBmodified SPCEs will be reviewed in this article, together with a recent application to determine aspartate aminotransferase (AST) in serum.
\end{abstract}

\section{Introduction}

The commercial drive to produce an inexpensive electrochemical biosensor has resulted in the development, to date, of the Exactech blood glucose monitor, widely used by diabetics [1]. The manufacturers of this device use screen-printing technology to produce the base transducer cheaply, allowing for disposal after each measurement $[2,3]$. The success of this device relies not only on the transducer, but also on the incorporation of an electrocatalyst together with the biorecognition element, glucose oxidase. In this case, the electron mediator, a ferrocene derivative, is included, facilitating electron transfer from the reduced oxidase enzyme to the electrode at an applied potential around $500 \mathrm{mV}$ below that required by glucose oxidase (via oxygen) alone. In this way, interference from other oxidisable species is considerably decreased, allowing operation of the device in whole blood.

A similar challenge is presented in developing biosensors based on the largest group of redox enzymes, the nicotinamide adenine dinucleotide $\left(\mathrm{NAD}^{+} / \mathrm{NADP}^{+}\right)$cofactordependent dehydrogenases [4]. These enzymes catalyse the oxidation of a number of biomedically important analytes and, in the process, convert the cofactor to its reduced form, NADH. Direct electrochemical measurement of NADH formation is possible by its oxidation at SPCEs, but this requires a high applied potential of about $+700 \mathrm{mV}$. Hence the development of viable screen-printed dehydrogenasebased biosensors for use in blood or plasma cannot proceed until a means of lowering the operating potential is achieved.

A number of electrocatalysts have been tested in conjunction with the dehydrogenases in order to reduce the 
required overpotential for oxidation of NADH. The main class of these is the organic mediators, including phenoxazines, phenazines and phenathiazines. The phenoxazine group includes compounds such as Meldola's Blue [5,6,7], and Nile Blue [8], the phenazines include the compound $\mathrm{N}$ methyl phenazinium ion $\left(\mathrm{PMS}^{+}\right)$[9] and the phenathiazines include Methylene Blue [9] and Toluidine Blue O [10].

Meldola's Blue (MB, 7-dimethyl-amino-1,2-benzophenoxazinium salt) is one of the most extensively studied electrochemical mediators used in the determination of NADH. Its structure is shown in figure 1.

The early electrochemical studies on this molecule, carried out by Gorton et al, involved the modification of bare planar graphite electrodes by rotating them $\left(\omega=99.2 \mathrm{rad} \mathrm{s}^{-1}\right)$ in a phosphate buffer containing $10^{-4} \mathrm{~mol} \mathrm{dm}^{-3} \mathrm{MB}$, prior to washing with de-ionized water [6]. Investigations into the electrochemical behaviour of the adsorbed MB highlighted its $\mathrm{pH}$-dependent reversible redox behaviour $\left(\mathrm{E}^{\mathrm{o} /}=+110 \mathrm{mV}\right.$ vs. SCE in $\left.0.1 \mathrm{~mol} \mathrm{dm}^{-3} \mathrm{HCl}\right)$, with a plot of $\mathrm{E}^{\mathrm{o} /}$ vs. $\mathrm{pH}$ showing two linear regions between $\mathrm{pH}$ 2.0-5.0 (slope $=$ $60 \mathrm{mV}$ per $\mathrm{pH}$ unit) and $\mathrm{pH} 5.0-10.0$ (slope $=30 \mathrm{mV}$ per $\mathrm{pH}$ unit). This behaviour was explained by the two equations below:

$\mathrm{pH}>5 \mathrm{MB}^{+}+\mathrm{H}^{+}+2 \mathrm{e}^{-}<=>\mathrm{MBH}$

$\mathrm{pH}<5 \mathrm{MB}^{+}+2 \mathrm{H}^{+}+2 \mathrm{e}^{-} \Leftrightarrow=\mathrm{MBH}^{+}$

and indicated a $p \mathrm{Ka}$ for adsorbed $\mathrm{MB}$ of around 5 in aqueous buffer. The mediator-modified electrodes were then placed in $\mathrm{pH} 7.0$ buffers containing either NADH or NADPH, where measurements were made using cyclic voltammetry. These studies showed an increase in the magnitude of the mediator redox waves compared to those seen in plain buffer solutions $\left(\mathrm{E}^{\mathrm{o} /},-175 \mathrm{mV} v s\right.$. $\left.\mathrm{SCE}\right)$, leading to a proposed scheme for the mediated reaction between $\mathrm{MB}$ and NADH (see following section).

Further work done by the same group [5] has shown that the reduction in overpotential due to the action of $\mathrm{MB}$ $(+550 \mathrm{mV})$ is greater than that caused by many other electrocatalytic molecules. $\mathrm{MB}$ is also more stable than many other commonly used mediators.

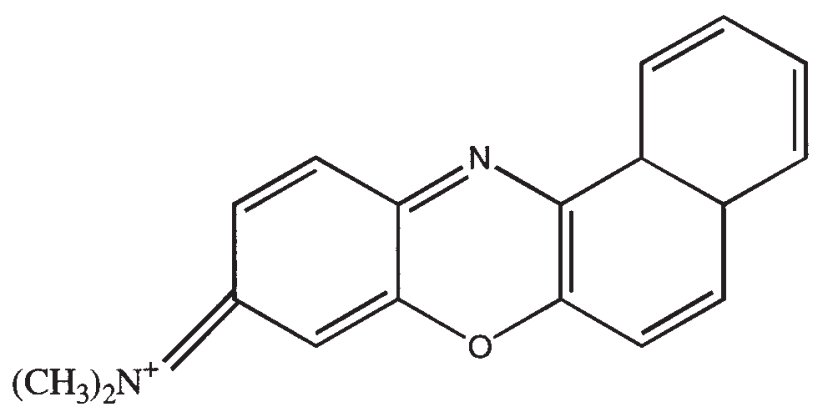

Figure 1. Structure of Meldola's Blue molecule.
These characteristics indicate that $\mathrm{MB}$ can be regarded as a good candidate mediator for use with dehydrogenase enzymes in the context of biosensor research. The following paragraphs review selected studies carried out at UWE, in which MB has been incorporated into screen-printing ink, firstly to develop a sensor for measuring the oxidation of NADH itself at low overpotential and then in its applications, with various co-immobilised dehydrogenase enzymes, to monitor bioanalytes.

\section{The NADH sensor}

At the outset, it was important to optimise the screen-printed base transducer before beginning experimental studies using MB. Several carbon-based screen-printed ink formulations were examined electrochemically by performing cyclic voltammetry in potassium hexacyanoferrate (II) solution [11]. Figure 2 illustrates representative voltammograms for two such inks, R14 and R17. From this study, it was evident from peak potential, peak separation and electron transfer coefficient $\left(\alpha n_{a}\right)$ values that the R14 ink produced the most rapid and reversible electron transfer characteristics. Consequently, this ink (referred to subsequently as D14) was selected for further work.

\section{Electrocatalytic ability of MB}

Using unmodified D14 SPCEs, it was possible to demonstrate the ability of $\mathrm{MB}$ in solution to act as an electrocatalyst for the oxidation of NADH. Figure $3 \mathrm{~b}$ shows that MB in bulk solution gave a reversible cyclic voltammogram, having an anodic peak at around $-100 \mathrm{mV}$. In the presence of excess NADH (Fig. 3a), this anodic peak increased in magnitude, whereas the cathodic peak disappeared, demonstrating the action of $\mathrm{MB}$ as a mediator for the transfer of electrons from NADH to the electrode. In the absence of $\mathrm{MB}$ (Fig. 3c), the oxidation of NADH was negligible at these potentials; an overpotential of $+0.7 \mathrm{~V}$ is required to oxidise NADH directly at SPCEs (not shown).

The sequence of events occuring during electrocatalytic oxidation of NADH by $\mathrm{MB}^{+}$was first described by Gorton et al. [6] and can be summarised as follows:

$$
\begin{aligned}
& \mathrm{NADH}+\mathrm{MB}^{+} \Leftrightarrow \mathrm{NADH} \cdot \mathrm{MB}^{+} \\
& \mathrm{NADH} \cdot \mathrm{MB}^{+} \Rightarrow \mathrm{NAD}+\mathrm{MBH} \\
& \mathrm{MBH} \Rightarrow \mathrm{MB}^{+}+2 \mathrm{e}^{-}+\mathrm{H}^{+}
\end{aligned}
$$

Chemical reaction between $\mathrm{NADH}$ and MB results in formation of the cofactor-mediator complex (Eq.3), which then dissociates to produce the reduced form of MB (Eq.4). The electrochemical oxidation of $\mathrm{MBH}$ (Eq.5) produces an analytical signal proportional in magnitude to initial NADH concentration. 


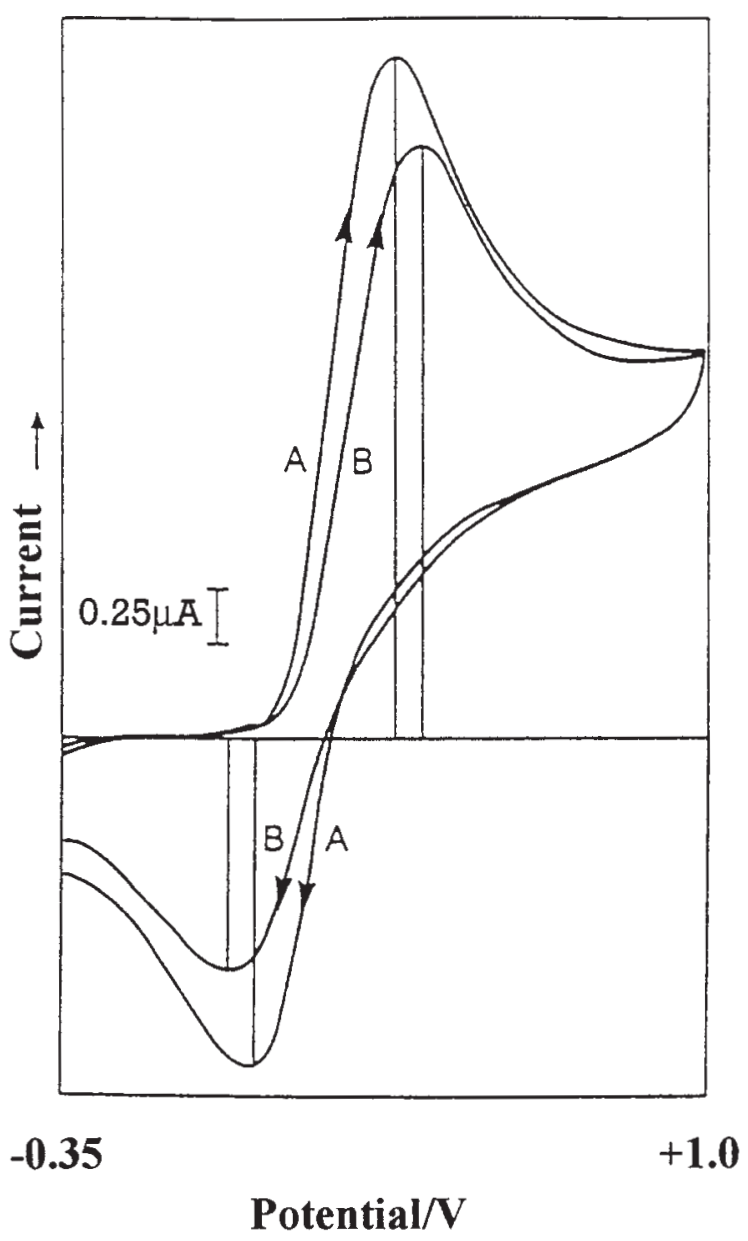

Figure 2. Comparison of screen-printed inks by cyclic voltammetry of potassium hexacyanoferrate (II). (A) C10903 R14 carbon ink electrode, (B) C10903 R17 carbon ink electrode. Voltammograms performed in $1 \times 10^{-3} \mathrm{~mol} \mathrm{dm}^{-3}$ potassium hexacyanoferrate (II) dissolved in $0.05 \mathrm{~mol} \mathrm{dm}^{-3}$ phosphate buffer, $\mathrm{pH}$ 7. Scan rate $=20 \mathrm{mV} \mathrm{s}^{-1}$. Reproduced from Sprules et al. (1994), with permission from the copyright holders, Royal Society of Chemistry.

\section{MB-modified SPCES}

Initial investigations were carried out using MB-modified electrodes prepared by mixing MB into D14 ink to a concentration of $5 \% \mathrm{~m} / \mathrm{m}$, prior to screen-printing. Electrocatalytic oxidation of NADH at these electrodes was clearly evident by cyclic voltammetry where an anodic peak appeared at a potential of $-0.05 \mathrm{~V} v s \mathrm{SCE}$ [11]. Amperometry in stirred solution was performed at this operating potential, and a linear response for NADH was obtained over the range $2.5 \times 10^{-6}$ to $2.5 \times 10^{-4} \mathrm{~mol} \mathrm{dm}^{-3}$; this clearly demonstrated the feasibility of using a MB-screen-printed sensor for $\mathrm{NADH}$ measurement. The effect of mediator loading over the range $1-5 \% \mathrm{~m} / \mathrm{m}$ is shown in figure 4 . Sensitivity increased with MB loading, up to a limit of around 5\%, at which point ink viscosity became prohibitively high for printing.
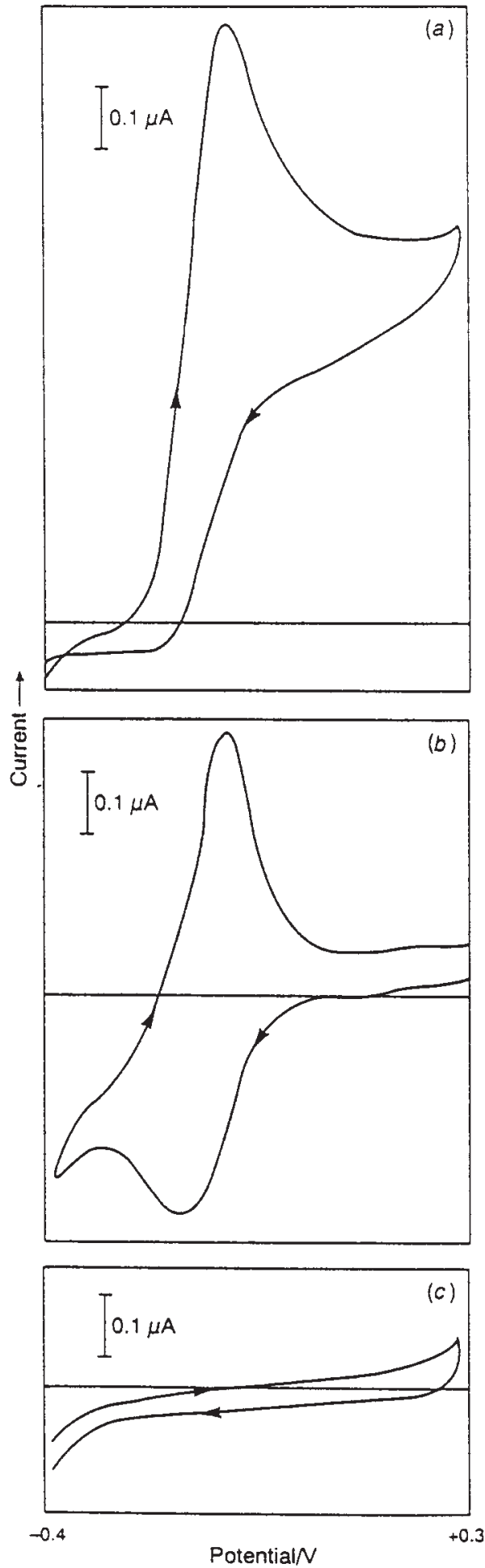

Figure 3. Mediated oxidation of NADH by dissolved Meldola's Blue. (a) $5 \times 10^{-5} \mathrm{~mol} \mathrm{dm^{-3 }}$ Meldola's Blue plus $6.4 \times$ $10^{-4} \mathrm{~mol} \mathrm{dm}^{-3} \mathrm{NADH}$, (b) $5 \times 1^{-5} \mathrm{~mol} \mathrm{dm}^{-3}$ Meldola's Blue and (c) $6.4 \times 10^{-4} \mathrm{~mol} \mathrm{dm}^{-3} \mathrm{NADH}$. All experiments in $0.05 \mathrm{~mol} \mathrm{dm}^{-3}$ phosphate buffer, $\mathrm{pH} 7$. Voltammetric conditions: -0.4 to $+0.3 \mathrm{~V}$ scan, $5 \mathrm{mV} \mathrm{s}^{-1}$. Reproduced from Sprules et al (1994), with permission from the copyright holders, Royal Society of Chemistry. 


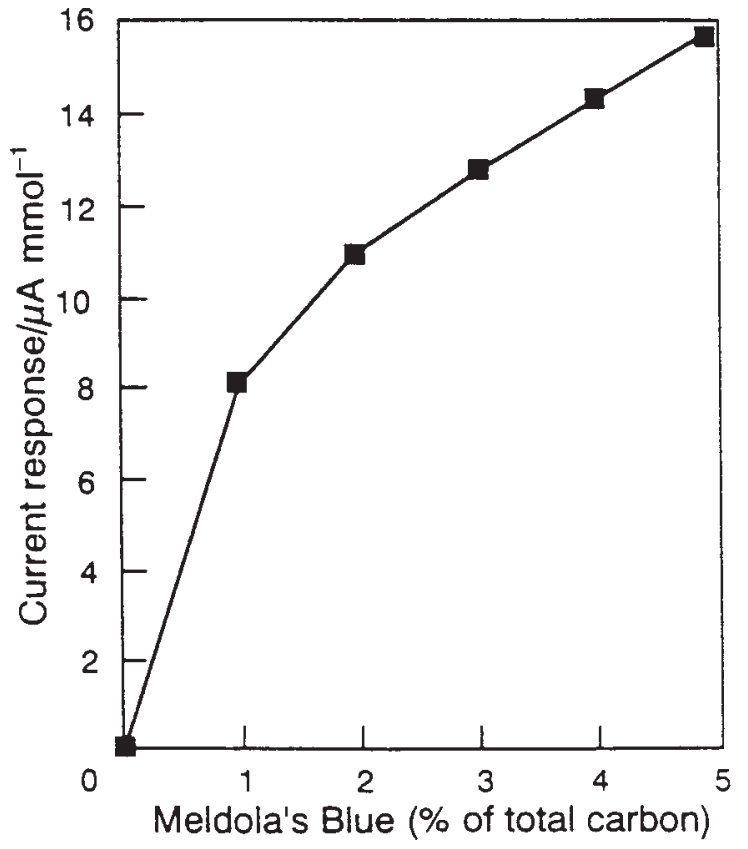

Figure 4. Effect of increasing mediator content in SPCEs on the sensitivity of their response to NADH. Concentrations of NADH used, $0.064-0.312 \mathrm{~mol} \mathrm{dm}{ }^{-3}$; applied potential, $-0.05 \mathrm{~V}$. Reproduced from Sprules et al (1994) with permission from the copyright holders, Royal Society of Chemistry.

\section{Biosensors incorporating MB-modified SPCES}

The following paragraphs describe the further development of the above NADH sensor, in combination with various dehydrogenase enzymes, to create prototype disposable biosensors for the measurement of several biomedically important analytes. In all of these studies, the D14 ink was modified with $2 \% \mathrm{MB}$, which provided sensors having the best sensitivity combined with good ink screen-printing quality and precision. The final example gives a detailed account of the various stages in the development of an AST biosensor which has not yet been reported.

\section{Lactate}

There is considerable interest in being able to monitor Llactate levels, both in biomedical and food application areas. In developing a prototype biosensor with the goal of convenient and portable monitoring, it has been possible to exploit the ability of the enzyme lactate dehydrogenase (LDH) to catalyse the transfer of a hydride ion $\left(\mathrm{H}^{-}\right)$from the substrate, L-lactate, to $\mathrm{NAD}^{+}$:

$$
\text { L-lactate }+\mathrm{NAD}^{+} \stackrel{(\mathrm{LDH})}{\Rightarrow} \text { pyruvate }+\mathrm{NADH}+\mathrm{H}^{+}
$$

The formation of NADH can be monitored electrocatalytically by oxidation at a MB-modified SPCE (see Eq. 3-5 above), thus providing a measure of the initial substrate concentration.

A prototype biosensor was constructed by manual deposition of optimised amounts of $\mathrm{LDH}$ and $\mathrm{NAD}^{+}$onto the surface of a SPCE containing $2 \% \mathrm{MB}$, followed by a membrane consisting of $1 \%$ cellulose acetate cast in situ [12]. This procedure resulted in a device capable of measuring lactate levels over the range $1-20 \mathrm{mM}$, using amperometry in stirred buffer solution at $0 \mathrm{~V} v s$ SCE in a three-electrode system. Under these conditions, the device was immune to electrochemical interference from uric acid, paracetamol, salicylate, methionine and gentisic acid, but was still capable of being influenced by ascorbic acid. A follow-up study [13] took the sensor a step closer to disposability and portability by screen-printing both working (D14 containing 2\% MB) and $\mathrm{Ag} / \mathrm{AgCl}$ reference electrodes onto the same sensor strip (Fig.5). In this case, the use of cellulose acetate to eliminate interferent species was not investigated. However, this dual electrode operated effectively in chronoamperometric mode, taking current measurements after 60s, and could be used to analyse the lactate content of small sample volumes $(20 \mu \mathrm{l})$. Calibration plots of biosensor responses for buffer and bovine serum spiked with lactate gave similar linear ranges $(1-20 \mathrm{mM})$. The response to lactate in serum was slightly less sensitive but showed no indication of non-selective responses to any electroactive interferent species. It was concluded that calibration plots obtained from spiked serum could readily be employed in the determination of lactate in unknown serum samples.

\section{Ethanol}

The brewing industry provides an example of an application area in which there is a need to develop a biosensor capable of on-site measurements. In the brewery itself, it is nec-

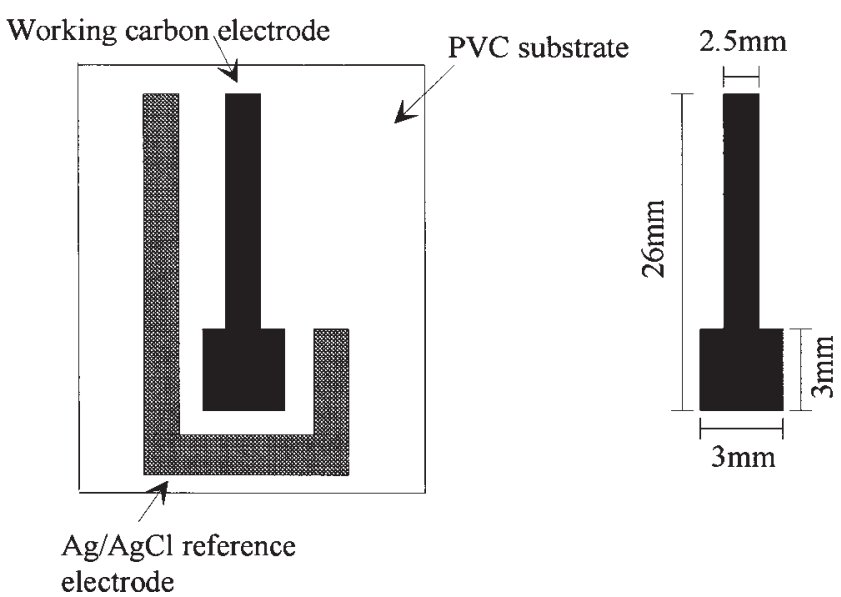

Figure 5. Diagrammatic representation of screen-printed electrodes on a PVC substrate showing electrode arrangement and dimensions. 
essary to monitor ethanol levels during production. Perhaps of greater interest in the present context, is the important market for such a device to guard against falsification of ethanol levels in beers and spirits after they have left the brewery or distillery.

A prototype alcohol biosensor has been developed in our laboratory [14] based on the oxidation of ethanol by the enzyme alcohol dehydrogenase $(\mathrm{ADH})$ :

$$
(\mathrm{ADH})
$$

Ethanol $+\mathrm{NAD}^{+} \Rightarrow$ Acetaldehyde $+\mathrm{NADH}+\mathrm{H}^{+}$(Eq.7)

The overall reaction scheme for the device, utilising SPCEs modified with MB, is summarised in figure 6 . The enzyme $(\mathrm{ADH})$ and its cofactor, $\mathrm{NAD}^{+}$, were dissolved in a phosphate buffer containing $10 \%$ trehalose as a stabiliser, and drop-coated onto the surface of an SPCE containing $2 \% \mathrm{MB}$. A membrane formed from a $1.25 \%$ solution of cellulose acetate was then cast in situ to contain these components, whilst allowing the passage of ethanol. The biosensor was operated using amperometry in stirred solution at a

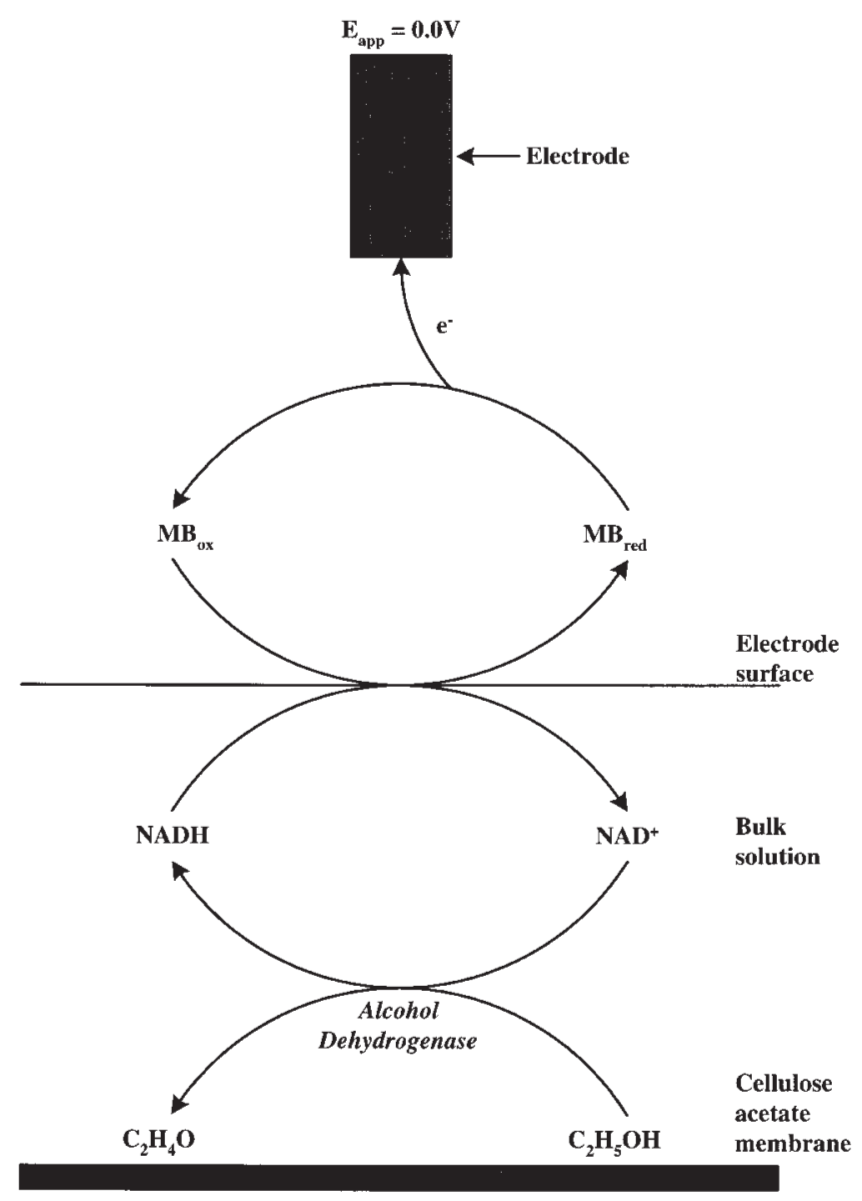

Figure 6. Reaction scheme for the amperometric alcohol biosensor. Reproduced from Sprules et al. (1996b) with permission from copyright holders, Elsevier Science B.V. Publishers. potential of $0 \mathrm{~V} v s . \mathrm{Ag} / \mathrm{AgCl}$ (this reference electrode was screen-printed as an integral part of the sensor). In this way it was possible to obtain a steady-state current reading after 3 min of operation. The sensor produced a linear response over the range 5 to $35 \mathrm{mM}$, which was then used to determine the concentration of ethanol in a commercial gin sample. Good agreement, with precision of $<5 \%$, was obtained with a recommended gas chromatographic method.

\section{Ammonia}

The determination of ammoniacal nitrogen $\left(\mathrm{NH}_{4}^{+}\right)$in river water is of environmental importance as elevated levels of this species may be indicative of pollution by domestic sewage and farm waste. The Environment Agency routinely monitors ammoniacal nitrogen using a colorimetric assay [15], but this determination has to be performed in the laboratory; a method which could be carried out in the field would therefore be highly desirable. As discussed above, screen-printed amperometric biosensors, having all the necessary reagents immobilised onto the device, offer the possibilty of such an assay. In addition, mass production using screen-printing technology allows fabrication at low cost; the biosensors could therefore be used once and discarded without the inherent problems of contamination. The prototype amperometric biosensor [16] was based on the following enzymatic reaction [17]:

$$
\begin{gathered}
\text { GLDH } \\
\mathrm{NADH}
\end{gathered}+\mathrm{NH}_{4}{ }^{+}+\text {2-oxoglutarate } \Rightarrow \text { glutamate }+\mathrm{NAD}^{+}+\mathrm{H}_{2} \mathrm{O} \text { (Eq.8) }
$$

where GLDH represents glutamate dehydrogenase. The measurement of $\mathrm{NH}_{4}^{+}$was again dependent on the detection of NADH by its electrocatalytic oxidation at the MB-SPCE. The maximum signal was obtained in the absence of ammonium ion and the current decreased with increasing concentrations of this species; the current difference was proportional to the concentration of $\mathrm{NH}_{4}^{+}$. The biosensor was used in conjunction with the chronoamperometric technique, offering the advantage of simplicity when required to be operated at the riverside. Determinations were carried out by depositing a $40 \mu \mathrm{l}$ sample aliquot onto the biosensor surface and applying a potential of $+0.05 \mathrm{~V} v s$. $\mathrm{Ag} / \mathrm{AgCl}$; the current was measured after a total time of $2.5 \mathrm{~min}$. Levels down to $2 \mu \mathrm{M}$ could be measured when the biosensor contained $4.6 \mathrm{U}$ of GLDH. The stability of the biosensors was examined after storage at $4^{\circ} \mathrm{C}$ in a desiccator containing silica gel; there was no deterioration in response over 29 days. The devices were evaluated on samples of spiked, and unspiked, river water samples and, as shown in Table I, reliable recovery and precision data were obtained for the river water studied.

\section{Recent study into an aspartate aminotransferase (AST) biosensor}

AST catalyses the transfer of an amino group from L-aspartate to $\alpha$-ketoglutarate and occurs in one of two forms, ie., cytoplasmic or membrane-bound mitochondrial. This enzyme 
Table I. Ammonium ion concentrations in unspiked and spiked river water samples.

\begin{tabular}{cccc}
\hline Sample no. & $\begin{array}{c}\text { Original } \\
\text { concn. } \\
(\mu M)\end{array}$ & $\begin{array}{c}\text { Concn. } \\
\text { added } \\
(\mu M)\end{array}$ & $\begin{array}{c}\text { Concn. } \\
\text { found } \\
(\mu M)\end{array}$ \\
\hline 1 & 9.0 & 1.3 & 10.3 \\
2 & 9.2 & 1.3 & 10.4 \\
3 & 9.1 & 1.3 & 10.5 \\
4 & 9.0 & 1.3 & 10.1 \\
5 & 9.0 & 1.3 & 10.4 \\
\hline
\end{tabular}

Mean original concentration $=9.06 \mathrm{mM}$

Mean found concentration $=10.34 \mathrm{mM}$

$\%$ Recovery $=98.5 \%$

is found in abundance in a variety of tissues throughout the human body and is at its highest concentration in heart muscle. It also occurs in serum, bile, cerebrospinal fluid and saliva, but not in non-pathological urine [18].

AST measurement is clinically important in the diagnosis of liver disease reflecting damage to hepatocytes $[19,20]$ but elevated levels are also found in myocardial infarction, circulatory failure and hypoxia [21]. A raised AST concentration can also be seen in other pathological conditions such as muscular dystrophies and skeletal muscle injuries [22]. Clearly, a simple, rapid assay for the determination of AST would be of considerable benefit for the possible diagnosis of such disorders.

The aim of this investigation was to explore the feasibility of measuring AST by utilizing a MB-modified SPCE, designed as an NADH sensor [5]. It was proposed that the NADH sensor would act as a base transducer in the measurement of AST through the reaction scheme shown in figure 7. In the absence of AST, the maximum current due to electrocatalytic oxidation of NADH is obtained. In the presence of AST, production of oxaloacetate occurs and this subsequently undergoes conversion to malate by malate dehydrogenase (MDH). The reduced cofactor is also required in this reaction and its disappearance results in a decrease in the electrocatalytic oxidation process involving MB. This decrease in current is directly proportional to the concentration of AST in serum samples.

\section{Sensor fabrication}

MB-SPCE's (containing 2\% MB) were modified by the application of a polycarbonate membrane $(0.4 \mu \mathrm{m}$ pore size, Whatman, Maidstone) over the surface of the working electrode. The purpose of this membrane was to decrease noise due to the stirrer and to increase the operational lifetime of the electrode by preventing the MB leaching from the carbon ink into the surrounding bulk solution [9]. The final area of the working electrode was $3 \times 3 \mathrm{~mm}$ and this was used in conjunction with a $\mathrm{Ag} / \mathrm{AgCl}$ reference electrode, also screenprinted on the same strip.

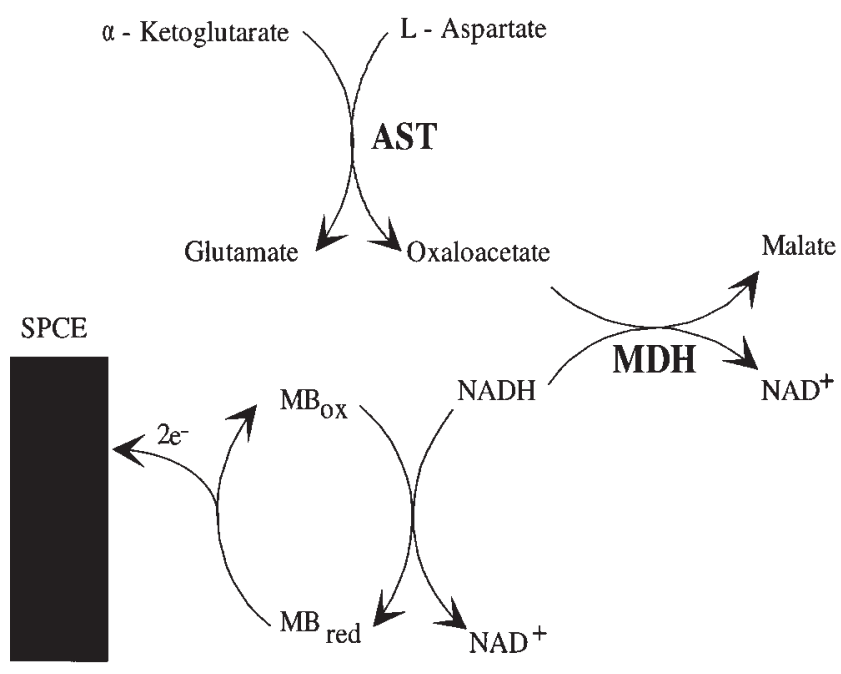

Figure 7. Proposed sequence of reactions involved in the AST sensor.

\section{Assay solutions and AST standards}

The supporting electrolyte used in these measurements consisted of potassium phosphate buffer $\left(0.1 \mathrm{~mol} \mathrm{dm}^{-3}, \mathrm{pH} 7.8\right)$. The assay solution was modelled on the components of a commercial kit for the colorimetric detection of AST (Sigma, Poole, Dorset, U.K.) and contained $0.2 \mathrm{~mol} \mathrm{dm}^{-3} \mathrm{~L}-$ aspartate, $0.012 \mathrm{~mol} \mathrm{dm}^{-3} \alpha$-ketoglutarate, $2.5 \times 10^{-4} \mathrm{~mol}$ $\mathrm{dm}^{-3} \mathrm{NADH}, 600 \mathrm{UL}^{-1} \mathrm{MDH}$ and $1 \times 10^{-4} \mathrm{~mol} \mathrm{dm}^{-3}$ pyridoxal-5-phosphate (P5P). The inclusion of P5P was based on the findings published by Bergmeyer [23]. The concentrations of L-aspartate and $\alpha$-ketoglutarate in the assay solution exceeded the $K_{m}$ values reported by Barman [24], thus ensuring that the AST introduced into the system was saturated with substrate and working at its maximal rate.

\section{Electrochemical assay of AST using reagents in solution}

A series of standards was prepared by spiking a pool of serum of known AST concentration (ie. $20 \mathrm{UL}^{-1}$ ) with additional enzyme. This produced a final concentration range between 20 and $1020 \mathrm{UL}^{-1}$ which encompassed both the clinical and pathological concentrations of the enzyme in serum.

Measurements were made using a commercial cell (Rank, Cambridge, U.K.) in conjunction with an EG\&G Model 264A potentiostat (Princeton, USA) connected to a Linseis LY17300 plotter (Recorderlab, Sutton, Surrey, U.K.). The applied potential was $+0.07 \mathrm{~V} v s$. $\mathrm{Ag} / \mathrm{AgCl}$. The temperature of the reaction mixture was kept constant at $30^{\circ} \mathrm{C}$ since this was the mid-point between the optimum operating temperatures of $\mathrm{AST}\left(37^{\circ} \mathrm{C}\right)$ and $\mathrm{MDH}\left(25^{\circ} \mathrm{C}\right)$.

Initially, a $2.5 \mathrm{ml}$ aliquot containing the appropriate concentration of reagents was equilibrated at $30^{\circ} \mathrm{C}$, with stirring, at a potential of $+0.07 \mathrm{~V} v s . \mathrm{Ag} / \mathrm{AgCl}$. After a steady-state 
current was achieved, an aliquot $(0.5 \mathrm{ml})$ of either standard or patient sample was added to the cell. The initial rate of current decrease was measured from the resulting amperogram and was used to construct a calibration plot or to determine unknown levels of AST in patient samples.

A linear response was obtained over the concentration range 20-1020 $\mathrm{UL}^{-1}\left(\mathrm{r}=0.997, \mathrm{r}^{2}=0.995\right)$ and the slope of the graph was $6.99 \times 10^{-3} \mathrm{nA} / \mathrm{sec} / \mathrm{UL}^{-1}$. The results obtained using the amperometric method were then compared with those found using a colorimetric method. Figure 8 shows that there was a reasonable agreement between these methods and suggests that the selected reagent concentrations were suitable for the amperometric assay. Based on these findings, it was decided to explore the posssiblity of immobilising one, or more, of the components of the AST assay onto the MB-SPCE.

\section{Electrochemical assay of AST using immobilised reagents}

The MB-SPCEs were initially modified by the application of a $10 \mu \mathrm{l}$ volume of MDH solution onto the surface of the working electrode, followed by a layer of Whatman 105 tissue [7]. The biosensors were then allowed to dry for four hours before any measurements were carried out. The application of the tissue facilitated the uniform spread, not only of the biorecognition element (ie. MDH) over the electrode, but also of the microlitre volumes of analyte deposited onto to the biosensor prior to measurement [7]. An incubation time of two minutes was used prior to application of the operating potential.

Initial studies were performed to optimise the concentration of NADH required for biosensor operation. Chronoamperometry was performed with a biosensor containing $10 \mathrm{U} \mathrm{MDH}$ and solutions containing a range of $\mathrm{NADH}$ concentrations $(0.1-10 \mathrm{mM})$ in the presence or

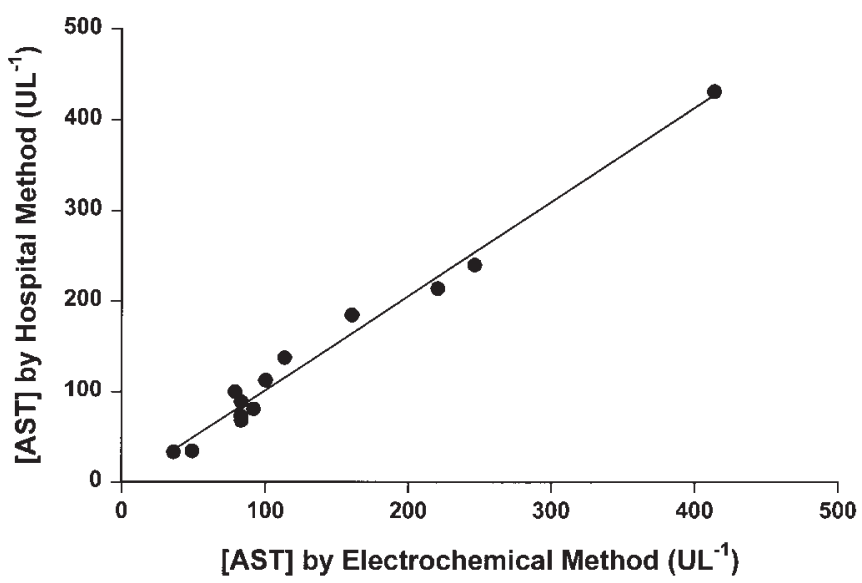

Figure 8. Correlation plot of the electrochemical method vs. the hospital colorimetric method, $y=1.04 \times-2.36, r=0.991$, $r^{2}=0.982$ absence of a fixed amount of oxaloacetate $(2.5 \mathrm{mM})$. The differences in the current for each NADH concentration are defined as $\Delta i$ values. Separate biosensors were used for each measurement with the applied potential being $-0.05 \mathrm{~V}$. This potential was different from that used earlier, since the presence of serum caused slight shifts in the position of the voltammetric wave. Figure 9 shows the plot of current response $(\Delta i) v s$. NADH concentration and from this graph a concentration of $7.5 \mathrm{mM}$ was selected for further studies.

A comparison between two MDH enzyme loadings (10 \& 20U) at different oxaloacetate concentrations was made; figure 10 shows the results. As there appeared to be little difference in sensitivity between the two biosensor enzyme loadings, 10U was selected for further studies.

In order to assess the ability of the biosensor to measure AST chronoamperometrically, the required concentrations of L-aspartate, $\alpha$-ketoglutarate and P5P were incubated in a separate reaction vessel at a temperature of $37^{\circ} \mathrm{C}$. The enzyme was added and after 2 minutes an aliquot $(20 \mu \mathrm{l})$ of the reaction mixture was deposited onto the biosensor surface. After a further 2 minutes of incubation to allow oxaloacetate to react, the operating voltage was initiated and the currents were recorded with time.

Figure 11 shows the resulting calibration plot. The data obtained over this limited concentration range indicate that the AST biosensor holds promise for applications in clinical analysis.

This study has demonstrated the possibility of measuring AST using an electrochemical approach. So far, AST activity has been measured indirectly via its ability to generate oxaloacetate; electrochemical detection has then been possible using essentially a disposable screen-printed oxaloacetate

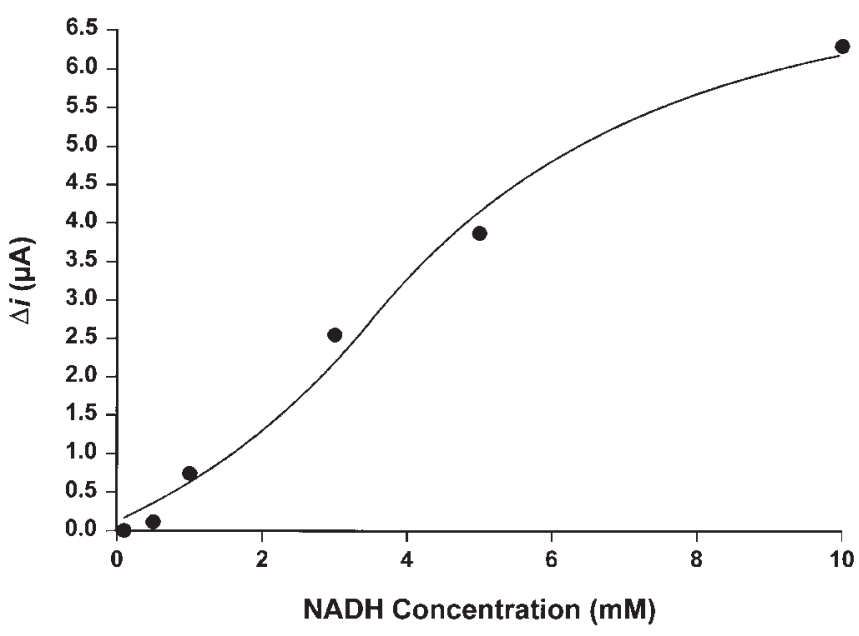

Figure 9. Determination of optimum NADH concentration for oxaloacetate base transducer using chronoamperometric detection method, $\mathrm{y}=0.65 \mathrm{x}+0.13, \mathrm{r}=0.988, \mathrm{r}^{2}=0.977$. $\mathrm{E}_{\mathrm{app}}=-0.05 \mathrm{~V}$ vs. $\mathrm{Ag} / \mathrm{AgCl}$, supporting electrolyte was $0.1 \mathrm{~mol} \mathrm{dm}^{-3}$ phosphate buffer, $\mathrm{pH}$ 7.8. Measurements taken at $10 \mathrm{~s}$. 


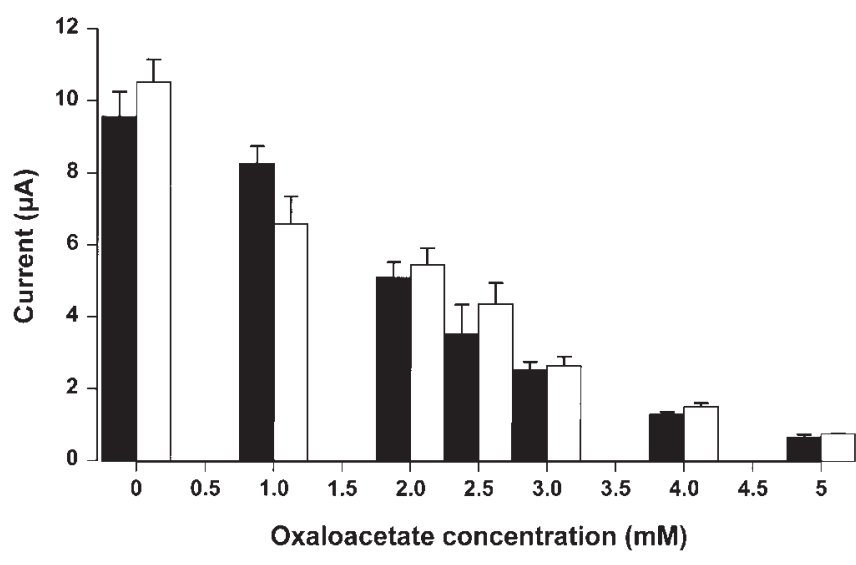

Figure 10. Histogram comparing the calibration and sensitivity of the oxaloacetate base transducer using different biosensor loadings of malate dehydrogenase. Solid bars correspond to a 10 unit per sensor loading $\left(y=-2.26 x+9.74, r=-0.986, r^{2}=\right.$ -0.972), open bars show response with a 20 unit per sensor loading $\left(\mathrm{y}=-2.19 \mathrm{x}+9.75, \mathrm{r}=-0.98, \mathrm{r}^{2}=-0.96\right)$. Eapp $=-0.05 \mathrm{~V}$ vs. $\mathrm{Ag} / \mathrm{AgCl}$, supporting electrolyte was $0.1 \mathrm{~mol} \mathrm{dm}^{-3}$ phosphate buffer, $\mathrm{pH}$ 7.8. Measurements taken at 10s. For each point $n=3$ (mean \pm sem).

biosensor. It is the aim of future work to develop a fullyintegrated AST biosensor by immobilising all of the reagents involved in the reaction sequence (Fig.7) onto the surface of a MB-SPCE.

\section{Acknowledgements}

The authors wish to thank Mr. R. Pittson and his staff at Gwent Electronic Materials for financial support of R.W. and for supplying screen-printed electrodes used in these studies. They are grateful to Mr. M. Gillet, Southmead Hospital, for providing serum samples for AST testing. Mr. M. Norman is acknowledged for assistance with the artwork.

\section{References}

1. Mathews, D.R.; Brown, E.; Watson, A.; Holman, R.R.; Steemson, J.; Hughes, S.; Scott, D. Lancet 1987, 1, 778-779.

2. Hart, J.P.; Wring, S.A. Electroanalysis 1994, 6, 617-624.

3. Hart, J.P.; Wring, S.A. Tr.A.C. 1997, 16, 89-103.

4. Wring, S.A.; Hart, J.P.; Pemberton, R.M.; Pittson, R.; Takahashi, L.; Tolan, J.; Serabjit-Singh, C. In Methodological Surveys in Bioanalysis of Drugs, vol 25. Eds: Reid, Hill \& Wilson, RSC. 1998, pp 159-165.

5. Gorton, L.; Faraday Trans. 1986, 82, 1245-1258.

6. Gorton, L.; Torstensson, A.; Jaegfeldt, H.; Johansson, G. J. Electroanal. Chem. 1984, 161, 103-120.

7. Appelqvist, R.; Marko-Varga, G.; Gorton, L.; Torstensson, A.; Johansson, G., Anal. Chim. Acta 1985, 169, 237-247.

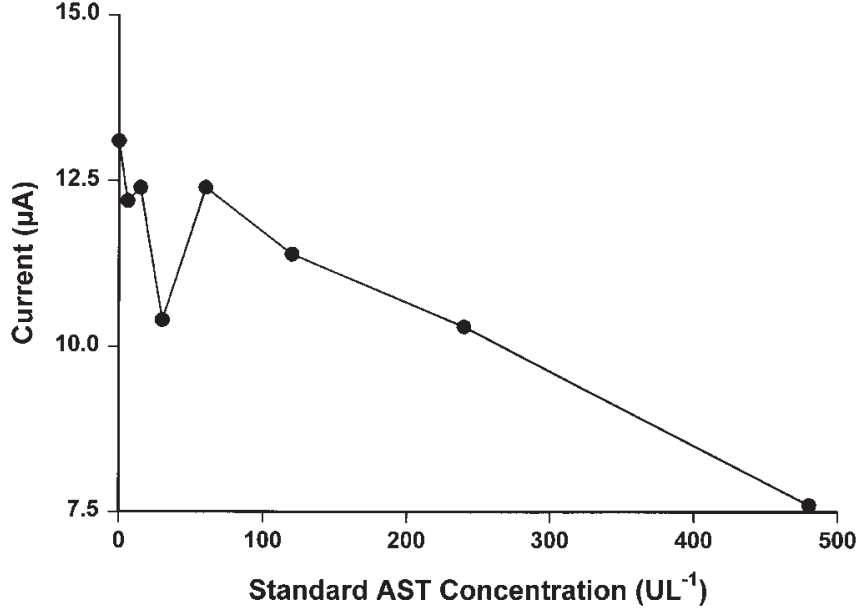

Figure 11. Chronoamperometric calibration of AST sensor. Sensor malate dehydrogenase loading is 10 units. $E_{\text {app }}=-0.05 \mathrm{~V}$ vs. $\mathrm{Ag} / \mathrm{AgCl}$, supporting electrolyte was $0.1 \mathrm{~mol} \mathrm{dm}^{-3}$ phosphate buffer, $\mathrm{pH}$ 7.8. Measurements taken at $10 \mathrm{~s}$.

8. Huck, H.; Schelter-Graf, A.; Danzer, J.; Kirch, P.; Schmidt, H-L. Analyst, 1984, 109, 147-150.

9. Ye, J.; Baldwin, R.P. Anal. Chem. 1988, 60, 2263-2268.

10. Persson, B. J. Electroanal. Chem. 1990, 287, 61-80.

11. Sprules, S.D.; Hart, J.P.; Wring, S.A; Pittson, R. Analyst 1994, 119, 253-257.

12. Sprules, S.D.; Hart, J.P.; Wring, S.A.; Pittson, R. Anal. Chim. Acta 1995, 304, 17-24.

13. Sprules, S.D.; Hart, J.P.; Pittson, R.; Wring, S. Electroanalysis, 1996, 6, 539-543.

14. Sprules, S.D.; Hartley, I.C.; Wedge, R.; Hart, J.P.; Pittson, R. Anal. Chim. Acta 1996b, 329, 215-221.

15. Water Analysis Handbook, 2nd Ed., 1992; Hach Company World Headquarters, 5600, Lindberg Drive, Loveland, Colorado, 80539, USA.

16. Hart, J.P.; Abass, A.K.; Cowell, D.C.; Chappell, A. Electroanalysis 1999, in press.

17. Abass, K.; Hart, J.P.; Cowell, D.C.; Chappell, A. Anal. Chim. Acta. 1998, 373, 1-8.

18. Ward, K.M.; Cockayne, S. In: Enzymology In Clinical Chemistry - Concepts and Applications (Anderson, S.C. \& Cockayne, S., eds) Saunders, 1993, pp 248-251.

19. Laker, M.F. BMJ 1990, 301, 250-251.

20. Whitby, L.G.; Smith, A.F.; Beckett, G.J. Lecture Notes On Clinical Biochemistry, Blackwell Scientific Publications, Oxford, 1994, Ed.5, p118.

21. Lott, J.A.; Stang, J.M. Clin. Chem. 1980, 26, 1241-1250.

22. Varley's Practical Clinical Biochemistry (Gowenlock, A.H., McMurray, J.R. \& McLauchlan, D.M., eds) Heinemann, London, 1988, p504.

23. Bergmeyer, H.U.; Scheibe, P.; Wahlefeld, A.W.; Clin. Chem. 1978, 24/1, 58-73.

24. Barman, T.E. Enzyme Handbook, Springer-Verlag, Berlin, 1969, 1, p.354. 